\title{
Chronic paranoid psychosis after misuse of MDMA ("ecstasy")
}

\author{
Philip McGuire, Tom Fahy
}

\begin{abstract}
Maudsley Hospital, London SE5 8SJ

Philip McGuire, MB, registrar in psychiatry
\end{abstract}

King's College Hospital and Institute of Psychiatry, London SE5

Tom Fahy, MRCPSYCH, lecturer in psychiatry

Correspondence to: $\mathrm{Dr}$ McGuire.

BMF 1991;302:697
3, 4-Methylenedioxymetamphetamine (MDMA, "ecstasy") is a hallucinogenic amphetamine that combines the effects of amphetamines and lysergic acid diethylamide (LSD) and has become increasingly popular in the United Kingdom. We report two cases of chronic paranoid psychoses after heavy misuse of this drug.

\section{Case reports}

CASE I

A 28 year old man was admitted after attempting to strangle his wife. He had been taking MDMA at weekends for 18 months. He had gradually increased his dose from two to 10 tablets a night and become suspicious that his wife was being unfaithful to him. He had checked on her movements, spied on her, and interrogated her and forced her to supply false confessions. Latterly he had supplemented his intake of MDMA with occasional doses of cocaine. He had stopped taking any drugs six weeks before his admission. He had experienced a brief paranoid psychosis eight years earlier after misusing amphetamines. His mother had suffered from schizophrenia.

Examination of his mental state showed prominent delusions of infidelity. Routine investigations, computed tomography of the brain, and serological tests for hepatitis B virus and HIV yielded normal results. He refused to provide a specimen of urine for drug screening. Treatment with haloperidol resulted in gradual improvement and he was discharged. Over the next seven months he twice relapsed and required readmission despite refraining from further use of drugs. On each admission urine specimens yielded negative results on drug screening.

CASE 2

A 22 year old man was admitted for assessment. Over the preceding two years he had consumed increasing quantities of MDMA with intermittent use of cocaine, lysergic acid diethylamide, and cannabis. Before admission he had been consuming three or four tablets of MDMA every night. He complained that his face had been gradually "pulled forward"; he avoided going out of doors, where he believed he was stared at and ridiculed. He had stopped misusing drugs (except cannabis) two weeks before admission. He had been adopted and had no knowledge of his biological family. He did not have a history of psychosis.

Examination of his mental state showed paranoid delusions and delusions of bodily change. Routine investigations, computed tomography of the brain, and serological tests for hepatitis B virus and HIV gave normal results. On admission his urine was positive for cannabis but negative for other drugs, and subsequent screens yielded negative results. His mental state did not improve, and he was treated with sulpiride. This was only partially effective, and he remained an inpatient three months after admission.

\section{Comment}

MDMA is a potent releaser of serotonin but also has dopaminergic actions. ${ }^{1}$ High doses in animals may be irreversibly toxic to serotoninergic neurones' ${ }^{1}$ experiments on primates suggest that this can occur at doses comparable with those taken by some drug misusers, and people who use MDMA may show evidence of impaired central serotoninergic function. ${ }^{3}$ Regular users develop tolerance and increase their intake, increasing the likelihood of adverse affects.

Misuse of MDMA has been associated with flashbacks, anxiety, confusion, and insomnia, ${ }^{4}$ but we have been unable to find reports linking it with psychosis. Both our patients developed chronic paranoid psychoses after prolonged misuse of MDMA, although they had also misused other drugs on occasion. Though acute paranoid psychoses are a well recognised complication of substance misuse, chronic cases are rare. Chronic psychoses after misuse of amphetamines have been attributed to the precipitation of schizophrenia in predisposed subjects. ${ }^{5}$ Chronic psychosis after misuse of MDMA, a derivative of amphetamine, might have a similar pathogenesis: the patient in case 1 , who had a personal and family history of psychosis and was later diagnosed as having schizophrenia. Given its capacity for neurotoxicity, however, MDMA might induce chronic psychosis de novo. An association with psychosis is particularly worrying because of the considerable increase in the use of the drug and its image as a fairly safe "recreational" substance.

We thank Professor R M Murray, Dr R W Kerwin, and Dr J W R Christie-Brown for giving us permission to report the cases.

ADDENDUM - We have subsequently seen a 38 year old man with a one year history of heavy misuse of MDMA, who presented with morbid jealousy and depression. He is currently undergoing assessment.

1 McKenna DJ, Peroutka SJ. Neurochemistry and neurotoxicity of 3,4 methylenedioxymetamphetamine (MDMA, "ecstasy"). f Neurochem 1990 54:14-22.

2 Ricaurte GA, DeLanney LE, Irwin I, Langston JW. Toxic effects of MDMA on central serotoninergic neurons in the primate: importance of route and frequency of administration. Brain Res 1988:446:165-8.

3 Price LP, Ricaurte GA, Krystal JH, Heninger GR. Neuroendocrine and mood response to intravenous I-tryptophan in 3,4-methylenedioxymetamphetaresponse to intravenous 1.-tryptophan in 3,4-methylencelis

4 Greer G Strassman RJ. Information on "ecstasy" Am f Psychiatry 1985;142: Greer G, Strass $1391-411$.

5 Connell PH. Amphetamine psychosis. Oxford: Oxford University Press; 1958 (Maudsley monograph No 5.)

(Accepted 16 fanuary 1991 )

\section{Correction}

Spontaneous pneumothorax: marker gas technique for predicting outcome of manual aspiration

An editorial error occurred in the discussion section of this paper by Dr Douglas Seaton and others (12 February, p 262). The fourth sentence of the second paragraph of the discussion should read, "The patients with pneumothoraces in which no marker gas was found did uniformly well and required only one aspiration without the need for tube drainage" and not ". . . did uniformly well, and aspiration without tube drainage was required for only one of them" as published. 